Check for updates

Cite this: RSC Adv., 2019, 9, 33388

\title{
Hydrothermal synthesis and competitive growth of flake-like $M$-type strontium hexaferrite $\dagger$
}

\begin{abstract}
Yilong Jing, (D) Lijun Jia, ${ }^{*}$ Yuhang Zheng and Huaiwu Zhang
In this paper, single flake-like strontium hexaferrite was directly synthesized via a modified hydrothermal approach without high-temperature annealing. To determine the main factors governing the formation of the hexaferrite phase and impurity $\alpha-\mathrm{Fe}_{2} \mathrm{O}_{3}$, effects of alkali environment and concentrations of metal ions on phase composition, grain growth, and magnetic properties were systematically analyzed. Results from XRD, FESEM and FT-IR analyses indicated that initial alkali concentration was the key factor influencing the phase composition of particles. Suitable initial alkali environment can enhance the nucleation and growth of ferrite, and inhibit the formation of by-product $\alpha-\mathrm{Fe}_{2} \mathrm{O}_{3}$ at the same time. It was also found that the increase in initial concentration of strontium ions could improve the nucleation of hexaferrite and reduce the grain size, and consequently, change the magnetic performance of hexagonal particles. When the molar ratios of ferric ions to strontium ions were constant, the average grain size did not change significantly with the initial concentration of iron ions, which could be attributed to high levels of strontium ions and hydroxyl ions in the reaction system. The abovementioned results indicate that the optimized hydrothermal conditions are beneficial for the formation of a single phase and for controlling the particle size and magnetic properties of M-type hexaferrite.
\end{abstract}

Received 11th August 2019

Accepted 19th September 2019

DOI: $10.1039 / \mathrm{c} 9 \mathrm{ra06246 \textrm {g }}$

rsc.li/rsc-advances inversion-induced magnetic hardening of nickel ferrite nanowires. Deng et al. ${ }^{21}$ found that introduction of $\mathrm{Zr}^{4+}$ ion in $\mathrm{BaFe}_{12} \mathrm{O}_{19}$ to substitute $\mathrm{Fe}^{3+}$ ion sharply decreased the coercivity while the saturation magnetization remained constant. Chen et al. ${ }^{22}$ reported that strontium ferrites/graphene $\left(\mathrm{SrFe}_{12} \mathrm{O}_{19} / \mathrm{G}\right)$ composites exhibited better absorption properties than pristine $\mathrm{SrFe}_{12} \mathrm{O}_{19}$ particles.

The low temperature hydrothermal synthesis technique for hexaferrite has attracted a great deal of research attention as it allows greater control over the crystalline structure and outward appearance. Studies have shown that high concentration of alkaline medium, long time of hydrothermal reaction (usually longer than 10 hours) at low temperatures $\left(180-240{ }^{\circ} \mathrm{C}\right.$ ), appropriate molar ratio of hydroxyl ions to nitrate radical ions $\left(R_{\mathrm{O} / \mathrm{N}}\right)$ and ferric ions to strontium ions $\left(R_{\mathrm{F} / \mathrm{S}}\right)$ are beneficial conditions for the synthesis of hexaferrite. However, even under these optimal conditions, traces of $\alpha-\mathrm{Fe}_{2} \mathrm{O}_{3}$ impurity are generally found in the product prepared by traditional hydrothermal synthesis. ${ }^{\mathbf{1 4 - 1 7}}$ Some attempts have been made to promote the formation of hexaferrite with high temperature annealing treatment (above $1000{ }^{\circ} \mathrm{C}$ ), but this method causes other problems, including poor uniformity of crystal dimensions. ${ }^{17,23,24}$ Another approach proposed to achieve quasi-pure M-type hexaferrite involves pretreatment with $\mathrm{CO}_{3}{ }^{2-}$-free alkaline solution, but the complicated operation makes this method unsuitable for practical application. ${ }^{25}$

In this work, a new approach was developed for the direct synthesis of pure M-type strontium hexaferrite through
State Key Laboratory of Electronic Thin Films and Integrated Devices, University of Electronic Science and Technology of China, Chengdu 610054, PR China. E-mail: jlj991210@163.com

$\dagger$ Electronic supplementary information (ESI) available. See DOI: 10.1039/c9ra06246g 
hydrothermal treatment without high-temperature annealing. The effects of alkali addition on the competitive growth of hexaferrite phase and the related mechanism were analyzed. Then, the relationship between the molar ratio of ferric ions to strontium ions $\left(R_{\mathrm{F} / \mathrm{S}}\right)$ and the micromorphology and magnetic properties of the assynthesized specimens was investigated and discussed.

\section{Experimental}

A series of M-type strontium ferrite $\left(\mathrm{SrFe}_{12} \mathrm{O}_{19}\right)$ crystal particles was prepared by hydrothermal synthesis using iron nitrate nonahydrate (AR 98.5\%), strontium nitrate (AR 99.5\%) and sodium hydroxide (AR 98.5\%) as the starting materials. A quantity of mixed metal ions solution was added gradually to alkaline solution and the mixture was allowed to react at room temperature under magnetic stirring. Then, the composite slurry was transferred into a reaction kettle with agitating device and heat-treated at $220^{\circ} \mathrm{C}$ for 2 hours. High purity nitrogen gas was charged into this closed system to regulate the initial pressure to 1.5 MPa. After the reaction was finished, the resultant precipitate was taken out from the kettle. Finally, the separated hexaferrite particles were washed several times with deionized water and absolute ethanol, dried at $80{ }^{\circ} \mathrm{C}$ and stored for subsequent use.

The crystalline phase of synthesized samples was identified by X-ray diffraction (XRD, Dandong DX-2700, China) using $\mathrm{CuK} \alpha$ radiation (wavelength $\lambda=1.5405 \AA$ ) and Fourier transform infrared spectroscopy (FT-IR, Thermo Scientific Nicolet 6700 , USA). The microstructures were observed by a field emission scanning electron microscope (FESEM, JSM-7500F, USA). The magnetic properties of powder samples were tested with vibrating sample magnetometer (VSM) with an applied field of 15 kOe. Raman spectra were recorded using a microRaman spectrometer (LabRAM HR Evolution, excitation wavelength of $633 \mathrm{~nm}$ ). The Curie temperature was established by Magnetic Thermogravimetric Analysis (MTGA) up to $800 \mathrm{~K}$ using a TA instruments thermobalance.

\section{Results and discussion}

\subsection{Effects of alkali environment on phase composition}

Fig. 1 shows the XRD patterns of the powders synthesized via hydrothermal process at $220^{\circ} \mathrm{C}$ for 2 hours, with different initial concentrations of ferric ions $\left(c_{\mathrm{Fe}}\right)$. The molar ratios of ferric ions to strontium ions $\left(R_{\mathrm{F} / \mathrm{S}}\right)$ and hydroxyl ions to nitrate radical ions $\left(R_{\mathrm{O} / \mathrm{N}}\right)$ in the reaction system were 8 and 1.6, respectively. It was found that the reactant concentration had a significant impact on the phase composition of products obtained by hydrothermal reaction. However, contrary to previous reports, the traces of by-product $\alpha-\mathrm{Fe}_{2} \mathrm{O}_{3}$ were only detected in the specimens with low reactant concentration. The reason for this phenomenon might be related to the nucleation and crystal growth of $\mathrm{SrFe}_{12} \mathrm{O}_{19}$ formed in alkaline system.

Similar to $\gamma-\mathrm{Fe}_{2} \mathrm{O}_{3}$ and $\alpha$-FeOOH, $\mathrm{Fe}(\mathrm{OH})_{3}\left(\right.$ or $\left.\mathrm{H}_{3} \mathrm{FeO}_{3}\right)$ in freshly prepared composite slurry is amphoteric and dissolves in hot alkaline solution to form tetrahydroxo ferrates (III), $\left[\mathrm{Fe}(\mathrm{OH})_{4}\right]^{-}(\mathrm{aq})$, i.e.

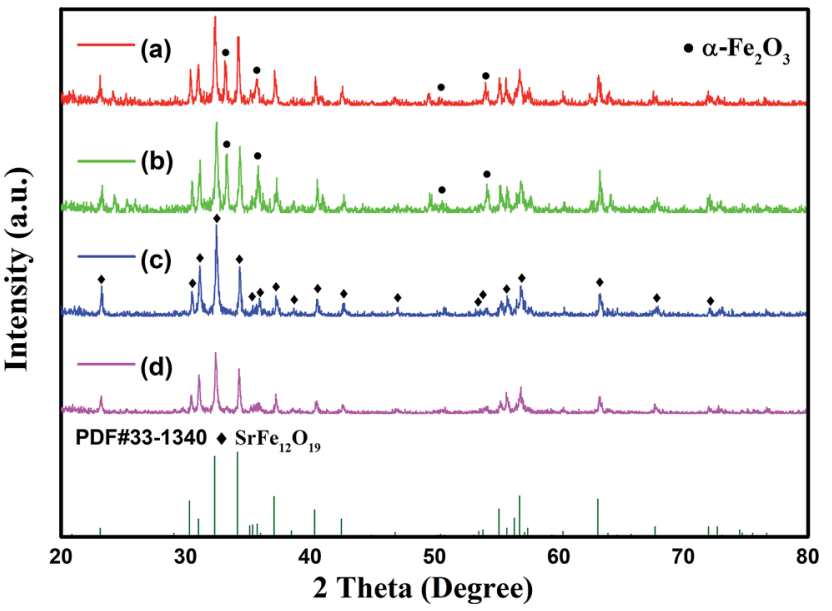

Fig. 1 XRD patterns of specimens with different initial concentration of ferric ions: (a) $0.25 \mathrm{~mol} \mathrm{~L}^{-1}$; (b) $0.375 \mathrm{~mol} \mathrm{~L}^{-1}$; (c) $0.5 \mathrm{~mol} \mathrm{~L}^{-1}$; (d) $0.625 \mathrm{~mol} \mathrm{~L}^{-1}$.

$$
\begin{gathered}
\mathrm{Fe}^{3+}(\mathrm{aq})+3 \mathrm{OH}^{-} \rightarrow \mathrm{H}_{3} \mathrm{FeO}_{3}(\mathrm{~s}) \\
\mathrm{H}_{3} \mathrm{FeO}_{3}(\mathrm{~s})+\mathrm{OH}^{-} \rightarrow\left[\mathrm{Fe}(\mathrm{OH})_{4}\right]^{-}(\mathrm{aq})
\end{gathered}
$$

The main product $\mathrm{SrFe}_{12} \mathrm{O}_{19}(\mathrm{~s})$ is expected from the reaction between $\left[\mathrm{Fe}(\mathrm{OH})_{4}\right]^{-}(\mathrm{aq})$ and hydrated strontium ions, $\mathrm{Sr}^{2+}(\mathrm{aq})$. The overall reaction in the kettle can be given by the following equation:

$19 \mathrm{H}_{2} \mathrm{O}$

$$
12\left[\mathrm{Fe}(\mathrm{OH})_{4}\right]^{-}(\mathrm{aq})+\mathrm{Sr}^{2+}(\mathrm{aq}) \rightarrow \mathrm{SrFe}_{12} \mathrm{O}_{19}(\mathrm{~s})+10 \mathrm{OH}^{-}+
$$

Combining eqn (1)-(3), an equation for the overall reaction can be given as:

$$
\mathrm{Sr}^{2+}(\mathrm{aq})+12 \mathrm{Fe}^{3+}(\mathrm{aq})+38 \mathrm{OH}^{-} \rightarrow \mathrm{SrFe}_{12} \mathrm{O}_{19}(\mathrm{~s})+19 \mathrm{H}_{2} \mathrm{O}
$$

However, side reactions may occur, especially when the conditions are less favorable for the synthesis of main product.

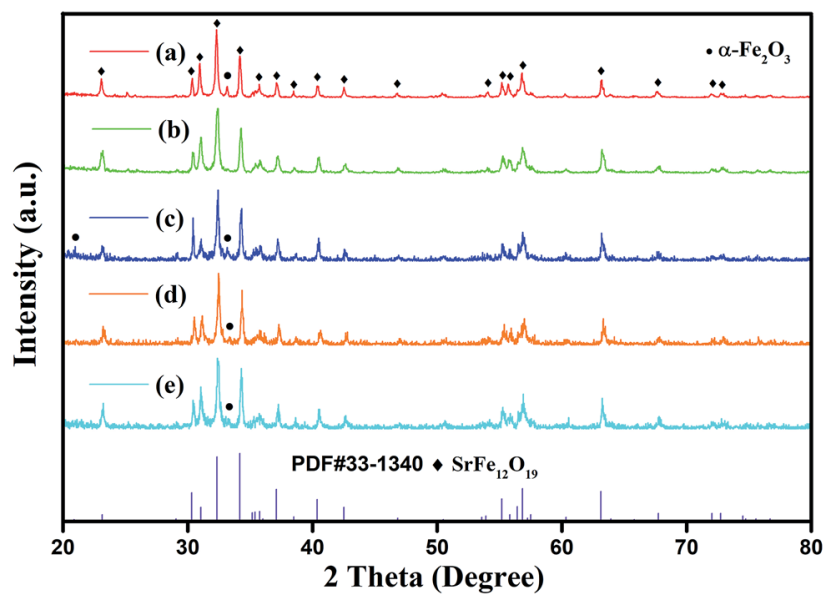

Fig. 2 XRD patterns of specimens with different initial concentration of hydroxyl ions: (a) $2.34 \mathrm{~mol} \mathrm{~L}^{-1}$ (b) $2.68 \mathrm{~mol} \mathrm{~L}^{-1}$ (c) $3.06 \mathrm{~mol} \mathrm{~L}^{-1}$ (d) $3.40 \mathrm{~mol} \mathrm{~L}^{-1}$ (e) $3.74 \mathrm{~mol} \mathrm{~L}^{-1}$. 
Table 1 Magnetic properties of strontium hexaferrite powders with different $C_{\mathrm{Fe}}$

\begin{tabular}{llll}
\hline$c_{\mathrm{Fe}}\left(\mathrm{mol} \mathrm{L}^{-1}\right)$ & $\sigma_{\mathrm{s}}\left(\mathrm{emu} \mathrm{g}^{-1}\right)$ & $\sigma_{\mathrm{r}}\left(\mathrm{emu} \mathrm{g}^{-1}\right)$ & $H_{\mathrm{c}}\left(\mathrm{kA} \mathrm{m}^{-1}\right)$ \\
\hline 0.2 & 48.41 & 16.17 & 74.3 \\
0.3 & 50.52 & 17.84 & 82 \\
0.4 & 50.84 & 17.52 & 81.9 \\
0.5 & 53.41 & 17.24 & 72.1 \\
0.6 & 50.16 & 16.81 & 76.4 \\
0.7 & 50.64 & 17.95 & 84.8
\end{tabular}

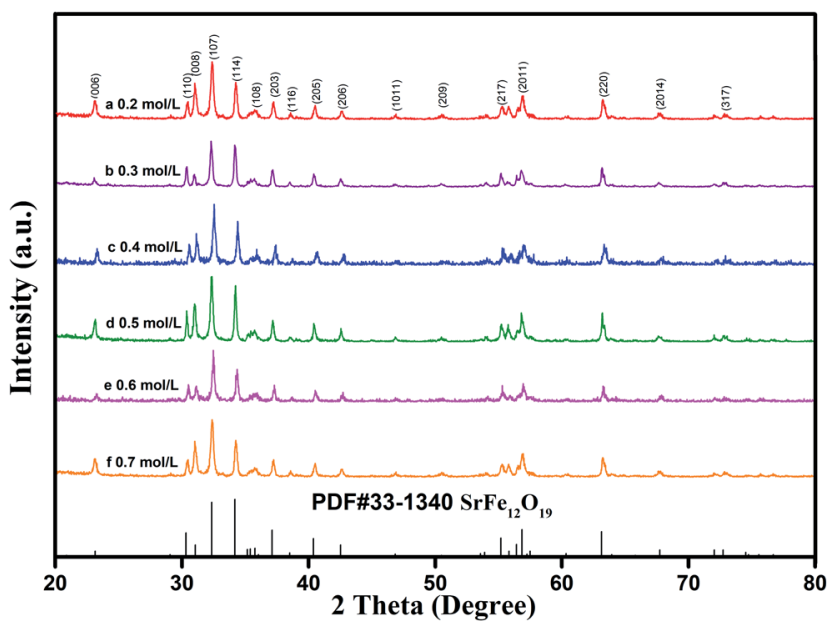

Fig. 3 XRD patterns of specimens with different initial concentration of ferric ions: (a) $0.2 \mathrm{~mol} \mathrm{~L}^{-1}$; (b) $0.3 \mathrm{~mol} \mathrm{~L}^{-1}$; (c) $0.4 \mathrm{~mol} \mathrm{~L}^{-1}$; (d) 0.5 $\mathrm{mol} \mathrm{L}$; (e) $0.6 \mathrm{~mol} \mathrm{~L}^{-1}$; (f) $0.7 \mathrm{~mol} \mathrm{~L}^{-1}\left(R_{\mathrm{F} / \mathrm{s}}=8\right)$.

$$
\left[\mathrm{Fe}(\mathrm{OH})_{4}\right]^{-}(\mathrm{aq}) \rightarrow \alpha-\mathrm{Fe}_{2} \mathrm{O}_{3}(\mathrm{~s})+2 \mathrm{OH}^{-}+\mathrm{H}_{2} \mathrm{O}
$$

According to the nucleation mechanism reported in previous studies, ${ }^{26-28},\left[\mathrm{Fe}(\mathrm{OH})_{4}\right]^{-}(\mathrm{aq})$ is aggregated into larger aggregates $\left[\mathrm{Fe}(\mathrm{OH})_{4}\right]_{x}^{x-}(\mathrm{aq})$ in the presence of $\mathrm{OH}^{-}$, which then react with $\mathrm{Sr}^{2+}(\mathrm{aq})$ ions, forming intermediate complexes and subsequently the target compounds. Increasing the reactant

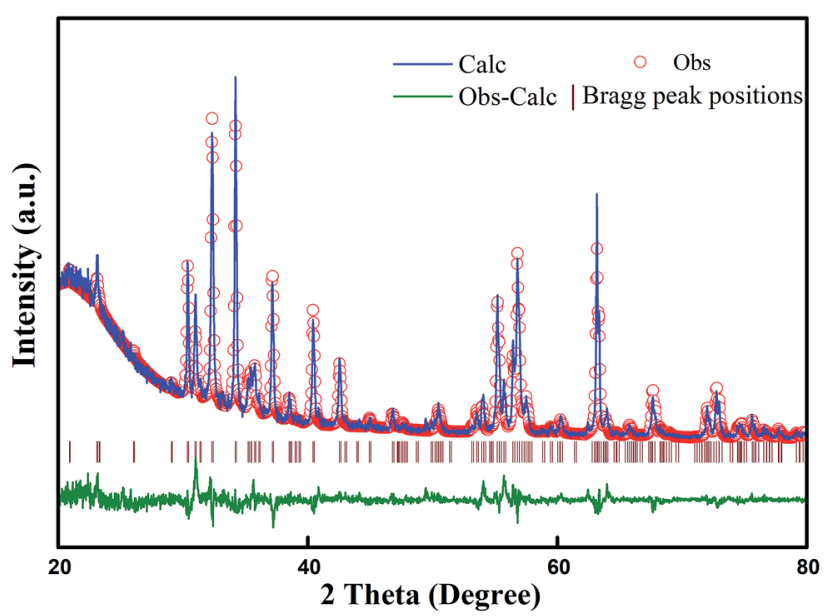

Fig. 4 The XRD pattern of sample $\left(0.5 \mathrm{~mol} \mathrm{~L}^{-1}\right)$ was fitted by Rietveld.
Table 2 Curie temperature and Rietveld parameters of crystal corresponds to the lattice parameters with different $C_{\mathrm{Fe}}$

\begin{tabular}{lcccccc}
\hline$x\left(\mathrm{~mol} \mathrm{~L}^{-1}\right)$ & 0.2 & 0.3 & 0.4 & 0.5 & 0.6 & 0.7 \\
$a / b(\AA)$ & 5.87 & 5.88 & 5.85 & 5.89 & 5.89 & 5.87 \\
$C(\AA)$ & 23.01 & 23.06 & 22.96 & 23.06 & 22.95 & 23.03 \\
$T_{\mathrm{c}}\left({ }^{\circ} \mathrm{C}\right)$ & 445.0 & 442.6 & 442.3 & 443.0 & 437.9 & 444.3 \\
\hline
\end{tabular}

concentration would increase the probability for successful collisions between the necessary constituent species needed for the formation of hexaferrite nuclei. On the other hand, the byproduct $\alpha-\mathrm{Fe}_{2} \mathrm{O}_{3}$ was formed because of the reduced concentration of $\mathrm{OH}^{-}$ions, as shown in Fig. 1(a) and (b). These results suggest that the alkaline environment plays an important role in the hydrothermal synthesis of hexaferrite.

On this basis, a simple empirical relation including the initial concentration of hydroxyl ions and the initial concentration of ferric ions in the reaction system was proposed for the hydrothermal synthesis of pure hexaferrite and the correctness of this formula was verified by experiments. The total content of hydroxyl ions can be divided into two parts: the quantity of consumed ions $\left(c_{\mathrm{OH}}^{\mathrm{con}}\right)$ and the remaining quantity $\left(c_{\mathrm{OH}}^{\mathrm{rem}}\right)$, i.e. $c_{\mathrm{OH}}$ $=c_{\mathrm{OH}}^{\mathrm{rem}}+c_{\mathrm{OH}}^{\mathrm{con}}$. From eqn (4),

$$
c_{\mathrm{OH}}^{\mathrm{con}}=\frac{38}{12} c_{\mathrm{Fe}} \approx 3.167 c_{\mathrm{Fe}} .
$$

Fig. 2 shows the XRD patterns of the as-synthesized powders with different initial concentrations of hydroxyl ions and constant $c_{\mathrm{Fe}}$ of $0.5 \mathrm{~mol} \mathrm{~L}^{-1}$ and $R_{\mathrm{F} / \mathrm{S}}$ of 8 . The XRD results showed that the main phase of all products was magnetoplumbite phase. Moreover, the impurity $\alpha-\mathrm{Fe}_{2} \mathrm{O}_{3}$ was detected in trace amounts in the specimens when the initial concentration of hydroxyl ions was greater than $2.68 \mathrm{~mol} \mathrm{~L}^{-1}$. This data can be used to calculate the value of $c_{\mathrm{OH}}^{\mathrm{rem}}$. Subsequently, the relationship between the optimum initial alkali concentration and the initial concentration of ferric ions in reaction system was obtained as follows:

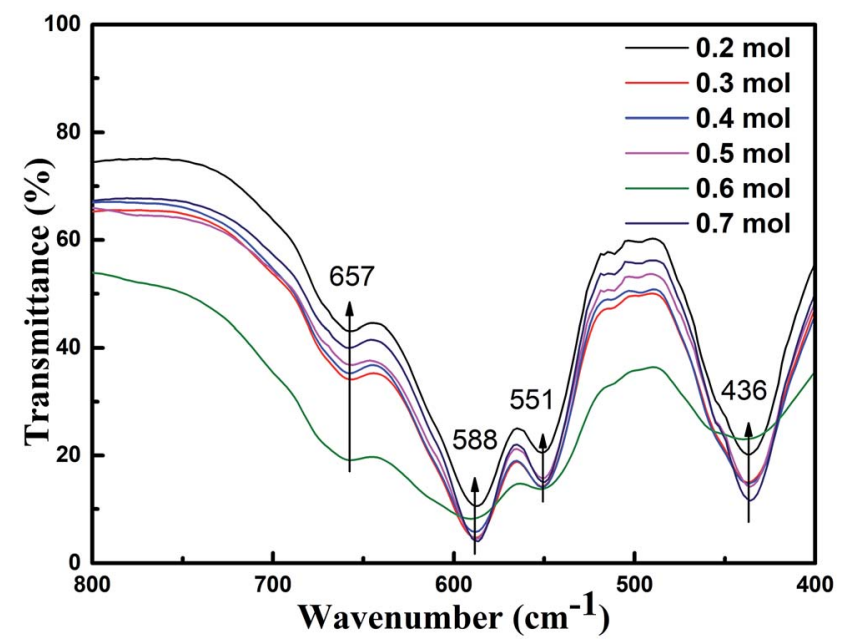

Fig. 5 FT-IR spectra of specimens with different concentration of ferric ions. 


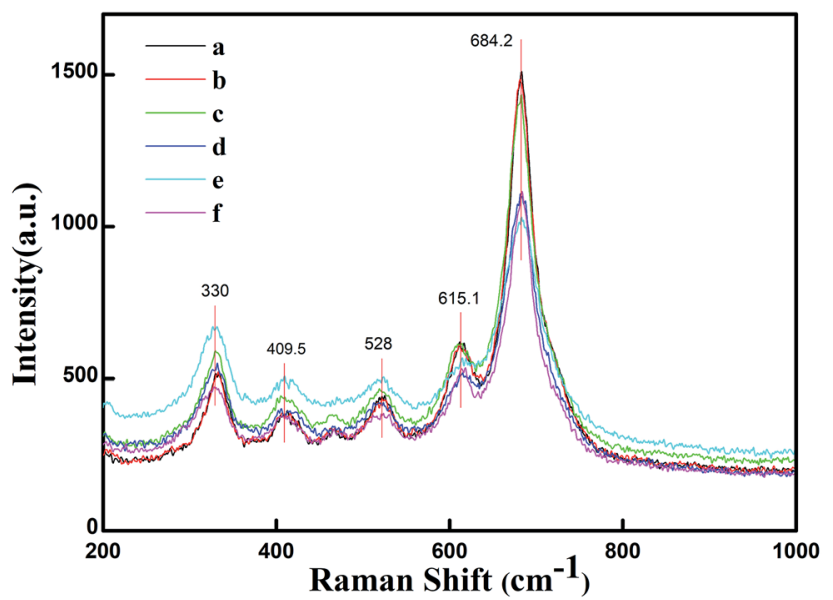

Fig. 6 Raman spectroscopy of specimens with different concentration of ferric ions.

$$
c_{\mathrm{OH}}=1.096+3.167 c_{\mathrm{Fe}}
$$

A set of experiments was designed to evaluate whether this formula was reasonable, and the corresponding results are given in Fig. 3-9 and Table 1. As shown in Fig. 3, only hexaferrite phase was detected in the XRD patterns without any impurity within the measurable limits. Fig. 4 shows the X-ray diffraction patterns of the sample (initial concentration of ferric ions is $0.5 \mathrm{~mol} \mathrm{~L}^{-1}$ ) and its corresponding Rietveld refinement mode. ${ }^{6}$ Table 2 shows the Curie temperature, the finishing parameters and the lattice constants of samples with initial ferric ions concentration between 0.2 to $0.7 \mathrm{~mol} \mathrm{~L}^{-1}$. It can be seen that with the increase in initial concentration of ferric ions, the unitcell parameters $a$ and $c$ changed only slightly and the Curie temperature of these samples also remained stable. ${ }^{29}$
Fig. 5 presents the FT-IR spectra in the range of 400$800 \mathrm{~cm}^{-1}$ for the specimens prepared with various initial concentrations of ferric ions. The FT-IR spectral data of the specimens were found to be in good agreement with the data reported in literature. ${ }^{14,30}$ The absorption bands at $551 \mathrm{~cm}^{-1}$, $588 \mathrm{~cm}^{-1}$ and $656 \mathrm{~cm}^{-1}$ could be assigned to the tetrahedral and octahedral sublattices of ferrite, respectively. The band at $436 \mathrm{~cm}^{-1}$ corresponds to the lattice vibration modes of characteristic fivefold ionic positions of hexaferrite. Fig. 6 presents the Raman spectra in the range of $200-1000 \mathrm{~cm}^{-1}$ for the specimens prepared with various initial concentrations of ferric ions. The Raman spectral data of the specimens were found to be in good agreement with the data reported in literature. ${ }^{31,32}$ The major peaks observed at about 684.2, 528, 409.5 and $330 \mathrm{~cm}^{-1}$ were consistent with the magnetoplumbite structure. The peaks at $684 \mathrm{~cm}^{-1}$ can be assigned to $\mathrm{Fe}-\mathrm{O}$ bonds at the tetrahedral $4 \mathrm{f} 1$ and bipyramidal $2 \mathrm{~b}$ sites. $^{33}$ From the abovementioned results, it can be concluded that suitable remaining concentration of hydroxyl ions in the reaction system can effectively inhibit the formation of by-product $\alpha-\mathrm{Fe}_{2} \mathrm{O}_{3}$.

Fig. 7(a)-(f) present the FESEM images of the products, which clearly show the presence of uniformly distributed hexagonal flakes about 2 microns in diameter. With increase in the $c_{\mathrm{Fe}}$, the average grain size did not change significantly. The room temperature special magnetic hysteresis $(\sigma-H)$ loops of the specimens with different values of $c_{\mathrm{Fe}}$ are shown in Fig. 8 and Table 1 . The magnetic properties of the specimens varied only slightly due to their similar composition and crystallinity. The specimen with $c_{\mathrm{Fe}}$ of $0.5 \mathrm{~mol} \mathrm{~L}^{-1}$ (S-0.5) exhibited special saturation magnetization $\left(\sigma_{\mathrm{s}}\right)$ of $53.41 \mathrm{emu}^{-1}$, remanent magnetization $\left(\sigma_{\mathrm{r}}\right)$ of $17.24 \mathrm{emu} \mathrm{g}^{-1}$, and coercive force $\left(H_{\mathrm{c}}\right)$ of $72.1 \mathrm{kA} \mathrm{m}^{-1}$. In order to verify the uniaxial anisotropy of $\mathrm{SrFe}_{12} \mathrm{O}_{19}$ hexagonal structure, the mixed slurry of powder S-0.5 and melted paraffin was coated and solidified on the glass slide. Then, magnetic field was applied perpendicular to the glass
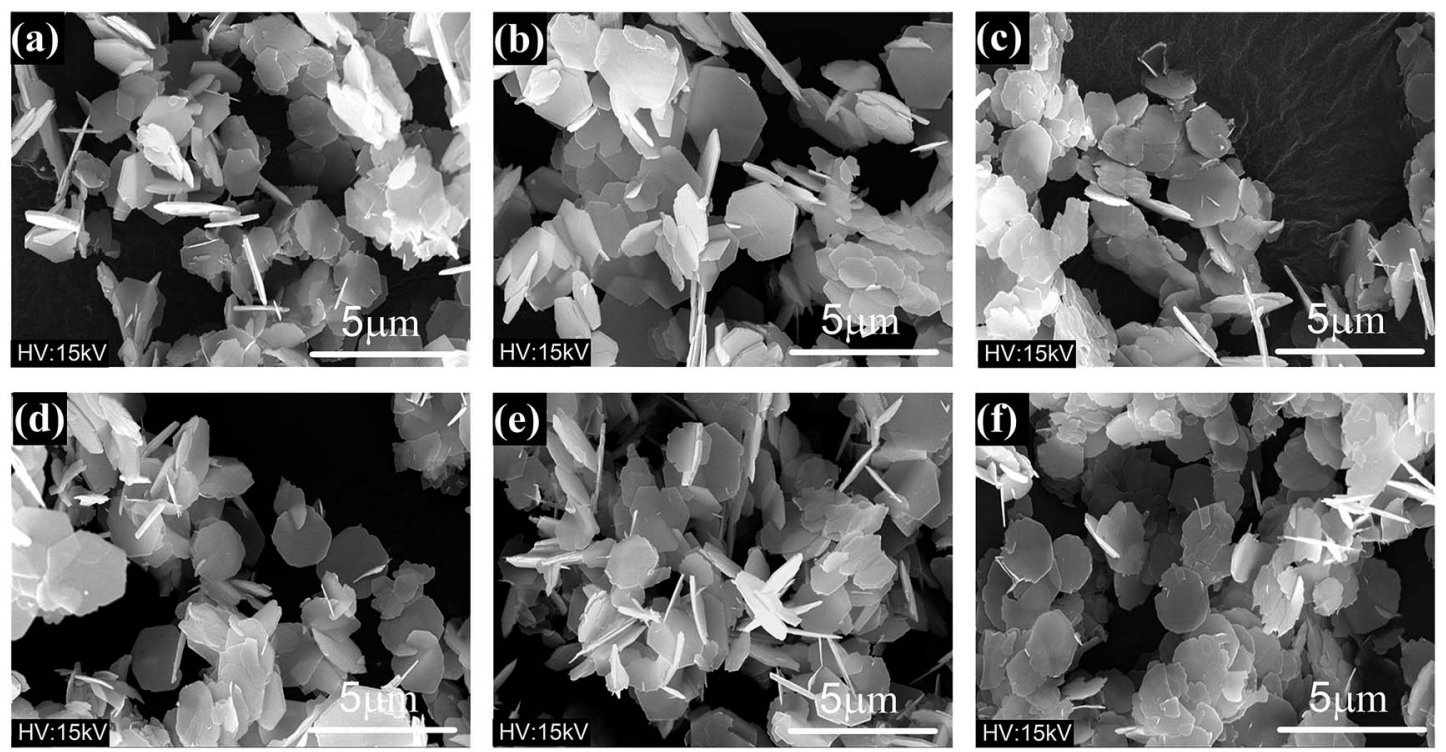

Fig. 7 Typical FESEM micrographs of specimens with various initial concentrations of ferric ions: (a) $0.2 \mathrm{~mol} \mathrm{~L}^{-1}$; (b) $0.3 \mathrm{~mol} \mathrm{L^{-1 }}$; (c) $0.4 \mathrm{~mol} \mathrm{~L}$; (d) $0.5 \mathrm{~mol} \mathrm{~L}^{-1}$; (e) $0.6 \mathrm{~mol} \mathrm{~L}^{-1}$; (f) $0.7 \mathrm{~mol} \mathrm{~L}^{-1}\left(R_{\mathrm{F} / \mathrm{S}}=8\right)$. 


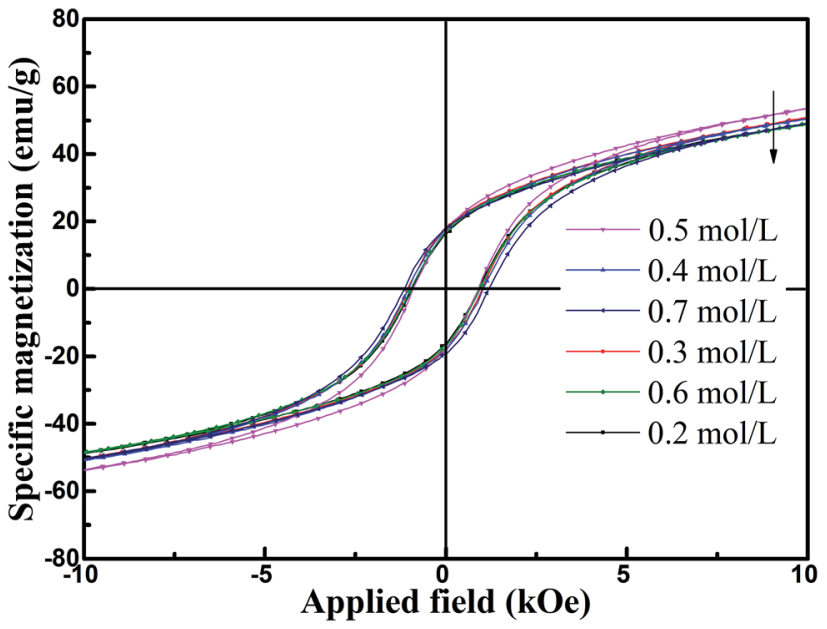

Fig. 8 Special magnetic hysteresis $(\sigma-H)$ loops of specimens with different initial concentration of ferric ions.

surface. Fig. 9 shows the hysteresis loops for a square piece of specimen with the field applied perpendicular or parallel to the glass surface. It can be seen from the loops that the easy magnetic axis was perpendicular to the glass surface and the hard magnetic axis was in the plane perpendicular to the easy magnetic axis at room temperature.

\subsection{Effects of the molar ratio of ferric ions to strontium ions on grain growth}

Fig. 10 shows the XRD patterns of the specimens with different molar ratios of ferric ions to strontium ions and fixed $c_{\mathrm{Fe}}$ of $0.5 \mathrm{~mol} \mathrm{~L}^{-1}$ and $c_{\mathrm{OH}}$ of $2.68 \mathrm{~mol} \mathrm{~L}^{-1}$. It was found that all the specimens were mainly composed of M-type hexaferrite phase. Traces of $\mathrm{SrCO}_{3}$ were observed in the specimens with higher initial concentrations of strontium ions $\left(c_{\mathrm{Sr}}\right)$ (Fig. 11(a) and (b)), which can be attributed to the side reaction of $\operatorname{Sr}(\mathrm{OH})_{2}$ with oxygen during the washing process. ${ }^{24}$

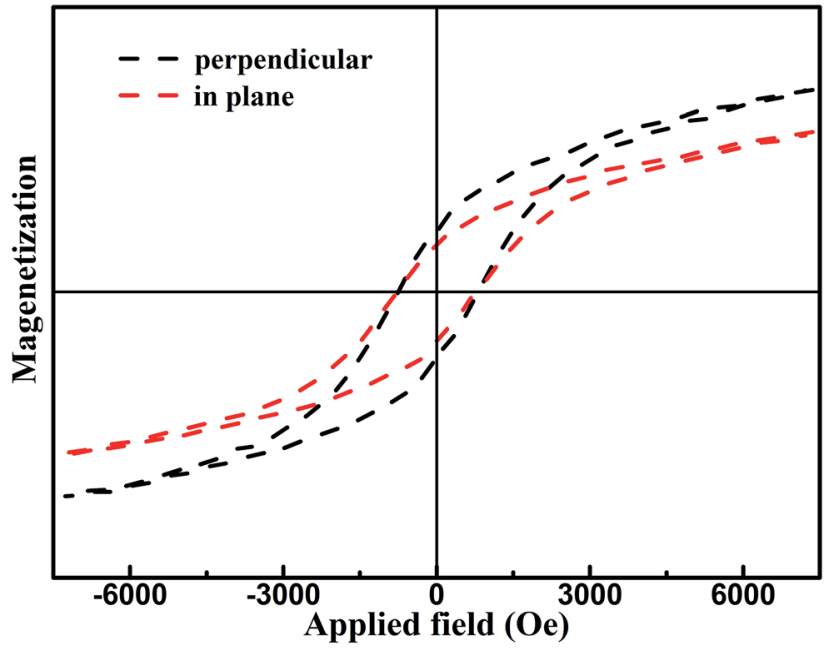

Fig. 9 Hysteresis loops obtained by vibrating sample magnetometer for the sample S- 0.5 oriented with magnetic field and congealed in paraffin.

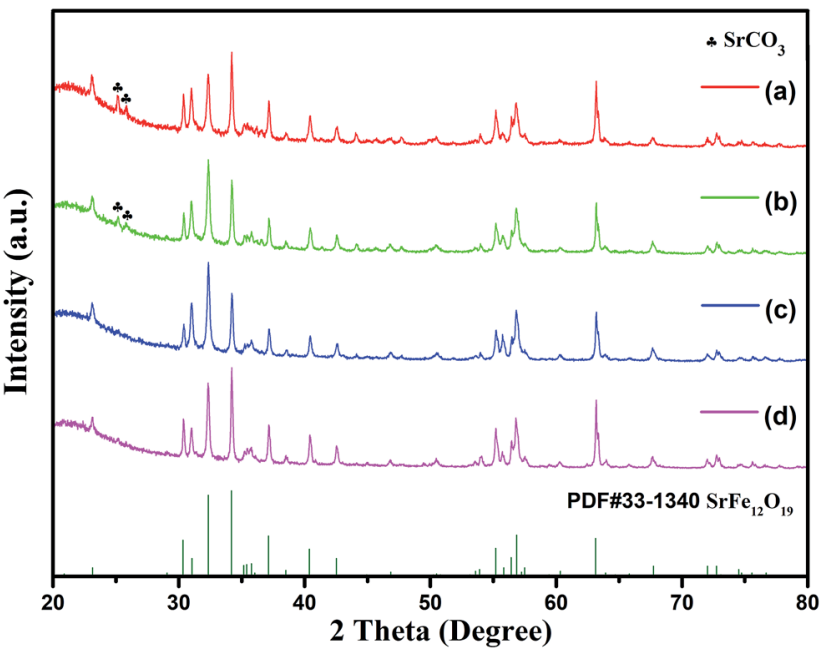

Fig. $10 X R D$ patterns of specimens with different molar ratios of ferric ions to strontium ions: (a) $R_{\mathrm{F} / \mathrm{S}}=2$; (b) $R_{\mathrm{F} / \mathrm{S}}=3$; (c) $R_{\mathrm{F} / \mathrm{S}}=4$; (d) $R_{\mathrm{F} / \mathrm{S}}=8$.

FESEM micrographs of the specimens prepared with different molar ratios of ferric ions to strontium ions are shown in Fig. 11. As the initial concentration of strontium ions increased, the average diameter of hexagonal flakes decreased from $\sim 2 \mu \mathrm{m}$ to $\sim 1 \mu \mathrm{m}$, and the thickness also reduced significantly. Namo measurement software was used to determine the average and the median thickness values of all flake-like M-type SrM in Fig. 11. It was found that both values were less than 0.1 $\mu \mathrm{m}$. M-type hexaferrite with lower Gibbs free energy is the thermodynamically preferred product compared with $\alpha-\mathrm{Fe}_{2} \mathrm{O}_{3} \cdot{ }^{25}$

The SrM structural unit consists of four parts, which are $S, R$, $S^{*}$ and $R^{*}{ }^{1}$ The ionic radius of $\mathrm{Sr}^{2+}(1.27 \AA)$ is similar to that of $\mathrm{O}^{2-}(1.38 \AA)$. It was assumed that in a hydrothermal environment, $\left[\mathrm{Fe}(\mathrm{OH})_{4}\right]^{-}(\mathrm{aq})$ is aggregated into larger aggregates $\left[\mathrm{Fe}(\mathrm{OH})_{4}\right]_{x}^{x-}(\mathrm{aq})$ in the presence of $\mathrm{OH}^{-}$. The higher temperature make $\mathrm{Sr}^{2+}$ substitute the position of $\mathrm{O}^{2-}$ in the crystal. This process destroyed the spinel structure which is already formed and results in the synthesis of $\mathrm{Sr}^{2+}$ layer which is equivalent to

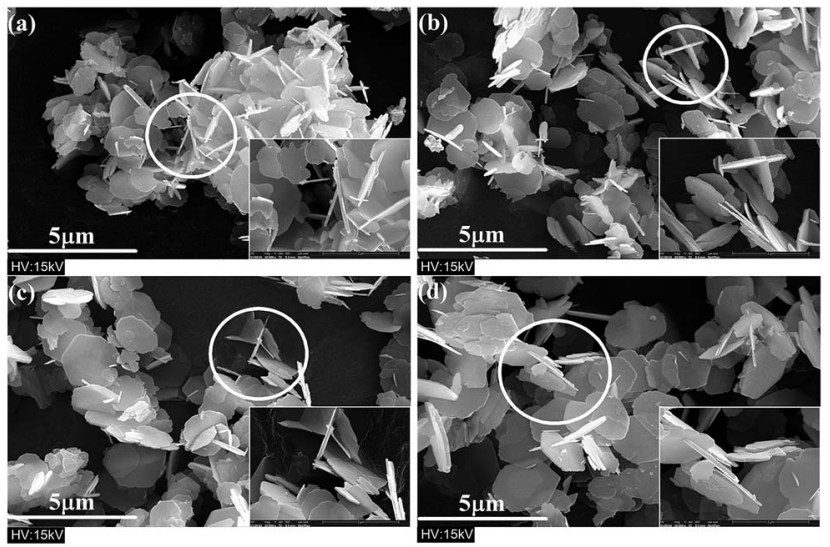

Fig. 11 FESEM micrographs of specimens with different molar ratios of ferric ions to strontium ions: (a) $R_{\mathrm{F} / \mathrm{S}}=2$; (b) $R_{\mathrm{F} / \mathrm{S}}=3$; (c) $R_{\mathrm{F} / \mathrm{S}}=4$; (d) $R_{\mathrm{F} /}$ $\mathrm{s}=8$. 
Table 3 Magnetic properties of strontium hexaferrite powders with different $R_{\mathrm{F} / \mathrm{S}}$

\begin{tabular}{llll}
\hline$R_{\mathrm{F} / \mathrm{S}}$ & $\sigma_{\mathrm{s}}\left(\mathrm{emu} \mathrm{g}^{-1}\right)$ & $\sigma_{\mathrm{r}}\left(\mathrm{emu} \mathrm{g}^{-1}\right)$ & $H_{\mathrm{c}}\left(\mathrm{kA} \mathrm{m}^{-1}\right)$ \\
\hline 2 & 32.6 & 14.5 & 95.7 \\
3 & 40.9 & 15.6 & 88.5 \\
4 & 48.8 & 16.3 & 83.6 \\
8 & 53.6 & 17.6 & 71.4
\end{tabular}

an intercalation layer. ${ }^{34}$ Through pyrolytic exfoliation, ${ }^{35,36}$ these intercalation layers induce the $\mathrm{M}$-type $\mathrm{Fe}_{2} \mathrm{O}_{3}$ platelets to be stripped and recombined into the required SrM platelets. ${ }^{7}$ It can be observed that some hexagonal crystals have small hexagonal thin layers attached to the surface (Fig. 11), which were interpreted as direct evidence.

Combined with the previous discussion, it can be concluded that at the right temperature, the reaction always proceeds in the direction of the synthetic SrM. The increase in concentration of $\mathrm{Sr}^{2+}$ ions accelerates this process. Consequently, more SrM can be synthesized by exfoliation and self-synthesis in a shorter period of time. It can be seen from eqn (3) that high concentration of strontium ions was favorable for the nucleation of hexaferrite at the same concentrations of $\mathrm{OH}^{-}$and $\left[\mathrm{Fe}(\mathrm{OH})_{4}\right]^{-}$, which could lead to small grain size.

The magnetic properties of these samples are listed in Table 3 . It can be seen that with the decrease in $c_{\mathrm{Sr}}$, the values of $\sigma_{\mathrm{s}}$ increased from 32.64 to $53.57 \mathrm{emu} \mathrm{g}^{-1}$ while the values of $H_{\mathrm{c}}$ decreased from 95.7 to $71.4 \mathrm{kA} \mathrm{m}^{-1}$, which was due to reduced size of hexaferrite flakes.

\section{Conclusion}

In this paper, single strontium hexaferrite was synthesized by a modified hydrothermal method. The effects of initial alkali environment and reactant concentration on phase formation, grain growth and magnetic properties of strontium hexaferrite were investigated in detail, and the related mechanism was studied. The results indicated that suitable initial alkali concentration promoted the nucleation and crystal growth of hexaferrite and inhibited the formation of by-product $\alpha-\mathrm{Fe}_{2} \mathrm{O}_{3}$. An empirical relation between initial alkali concentration and initial concentration of ferric ions in reaction system was summed up for the efficient hydrothermal synthesis of pure hexaferrite, and its rationality was verified by experiments. The hexagonal particles with pure SrM phase and uniform size distribution were synthesized by the optimized process. It was also found that the initial concentration of strontium ions could effectively modulate the grain growth and magnetic properties. Thus, optimizing the hydrothermal synthesis conditions, especially initial alkali concentration and initial concentration of strontium ions, can improve the preparation of M-type hexaferrite for microwave and millimeter-wave applications.

\section{Conflicts of interest}

There are no conflicts to declare.

\section{Acknowledgements}

This work was partly supported by the National Natural Science Foundation of China under Grant No. 51572041, the Sichuan Science and Technology Supporting Program under Grant No. 2017HH0052, and the National Key Scientific Instrument and Equipment Development Project under Grant No. 51827802.

\section{References}

1 R. C. Pullar, Hexagonal ferrites: A review of the synthesis, properties and applications of hexaferrite ceramics, Prog. Mater. Sci., 2012, 57, 1191-1334.

2 G. Asghar and M. Anis-ur-Rehman, Structural, dielectric and magnetic properties of $\mathrm{Cr}-\mathrm{Zn}$ doped strontium hexa-ferrites for high frequency applications, J. Alloys Compd., 2012, 526, 85-90.

3 S. M. Abbas, A. K. Dixit, R. Chatterjee and T. C. Goel, Complex permittivity, complex permeability and microwave absorption properties of ferrite-polymer composites, $J$. Magn. Magn. Mater., 2007, 309, 20-24.

4 A. Ghasemi, A. Hossienpour, A. Morisako, A. Saatchi and M. Salehi, Electromagnetic properties and microwave absorbing characteristics of doped barium hexaferrite, $J$. Magn. Magn. Mater., 2006, 302, 429-435.

5 J. X. Qiu, M. Y. Gu and H. G. Shen, Microwave absorption properties of Al- and Cr-substituted M-type barium hexaferrite, J. Magn. Magn. Mater., 2005, 295, 263-268.

6 Y. Chen, Y. Wang, Y. Liu, Q. Liu, C. Wu, B. Qi and H. Zhang, Microstructure and magnetic properties of $\mathrm{Y}$ substituted $\mathrm{M}$ type hexaferrite $\mathrm{BaY}_{x} \mathrm{Fe}_{12-x} \mathrm{O}_{19}$, J. Mater. Sci.: Mater. Electron., 2019, 30, 5911-5916.

7 K. K. Mallick, P. Shepherd and R. J. Green, Dielectric properties of M-type barium hexaferrite prepared by coprecipitation, J. Eur. Ceram. Soc., 2007, 27, 2045-2052.

8 Z. F. Zi, Y. P. Sun, X. B. Zhu, Z. R. Yang, J. M. Dai and W. H. Song, Structural and magnetic properties of $\mathrm{SrFe}_{12} \mathrm{O}_{19}$ hexaferrite synthesized by a modified chemical co-precipitation method, J. Magn. Magn. Mater., 2008, 320, 2746-2751.

9 M. M. Hessien, M. M. Rashad and K. El-Barawy, Controlling the composition and magnetic properties of strontium hexaferrite synthesized by co-precipitation method, $J$. Magn. Magn. Mater., 2008, 320, 336-343.

10 V. Harikrishnan, P. Saravanan, R. E. Vizhi, D. R. Babu, V. T. P. Vinod, P. Kejzlar and M. Cernik, Effect of annealing temperature on the structural and magnetic properties of CTAB-capped $\mathrm{SrFe}_{12} \mathrm{O}_{19}$ platelets, J. Magn. Magn. Mater., 2016, 401, 775-783.

11 G. B. Teh, Y. C. Wong and R. D. Tilley, Effect of annealing temperature on the structural, photoluminescence and magnetic properties of sol-gel derived Magnetoplumbitetype (M-type) hexagonal strontium ferrite, J. Magn. Magn. Mater., 2011, 323, 2318-2322.

12 R. C. Pullar, M. D. Taylor and A. K. Bhattacharya, Novel aqueous sol-gel preparation and characterization of 
barium $\mathrm{M}$ ferrite, $\mathrm{BaFe}_{12} \mathrm{O}_{19}$ fibres, J. Mater. Sci., 1997, 32, 349-352.

13 L. Lechevallier, J. M. Le Breton, J. F. Wang and I. R. Harris, Structural analysis of hydrothermally synthesized $\mathrm{Sr}_{1-x} \mathrm{Sm}_{x} \mathrm{Fe}_{12} \mathrm{O}_{19}$ hexagonal ferrites, J. Magn. Magn. Mater., 2004, 269, 192-196.

14 J. H. Lee, H. S. Kim and C. W. Won, Magnetic properties of strontium ferrite powder made by hydrothermal processing, J. Mater. Sci. Lett., 1996, 15, 295-297.

15 Y. Li, A. Xia and C. Jin, Synthesis, structure and magnetic properties of hexagonal $\mathrm{BaFe}_{12} \mathrm{O}_{19}$ ferrite obtained via a hydrothermal method, J. Mater. Sci.: Mater. Electron., 2016, 27, 10864-10868.

16 D. Guo, P. Zhou, J. Hou, X. Luo, X. Wang and L. Deng, Compositional Control and Millimeter-Wave Properties of Micro-/Nano-Sized M-Type Barium Hexaferrite Synthesized by Hydrothermal Method, IEEE Trans. Magn., 2015, 51(11), 1-4.

17 M. Jean, V. Nachbaur, J. Bran and J.-M. Le Breton, Synthesis and characterization of $\mathrm{SrFe}_{12} \mathrm{O}_{19}$ powder obtained by hydrothermal process, J. Alloys Compd., 2010, 496, 306-312.

18 P. Y. Meng, K. Xiong, K. Ju, S. N. Li and G. L. Xu, Wideband and enhanced microwave absorption performance of doped barium ferrite, J. Magn. Magn. Mater., 2015, 385, 407-411.

19 S. V. Trukhanov, A. V. Trukhanov, V. G. Kostishyn, L. V. Panina, A. V. Trukhanov, V. A. Turchenko, D. I. Tishkevich, E. L. Trukhanova, V. V. Oleynik, O. S. Yakovenko, L. Y. Matzui and D. A. Vinnik, Magnetic, dielectric and microwave properties of the $\mathrm{BaFe}_{12-x} \mathrm{Ga}_{x} \mathrm{O}_{19}$ $(x<=1.2)$ solid solutions at room temperature, J. Magn. Magn. Mater., 2017, 442, 300-310.

20 J. M. Li, X. L. Zeng and Z. A. Xu, Partial cationic inversioninduced magnetic hardening of densely packed 23-nmsized nanocrystallite-interacting nickel ferrite electrospun nanowires, Appl. Phys. Lett., 2013, 103, 5.

21 L. Deng, Y. Zhao, Z. M. Xie, Z. H. Liu, C. Y. Tao and R. R. Deng, Magnetic and microwave absorbing properties of low-temperature sintered $\mathrm{BaZr}_{x} \mathrm{Fe}_{(12-x)} \mathrm{O}_{19}, R S C$ Adv., 2018, 8, 42009-42016.

22 W. Chen, Q. Y. Liu, X. X. Zhu and M. Fu, One-step in situ synthesis of strontium ferrites and strontium ferrites/ graphene composites as microwave absorbing materials, RSC Adv., 2017, 7, 40650-40657.

23 C. Zhang, X. Liu, K. M. U. Rehman, C. Liu, H. Li and X. Meng, Structural and properties of hydrothermally synthesised Mtype hexaferrites, J. Mater. Sci.: Mater. Electron., 2017, 28, 4593-4597.
24 A. Xia, C. Zuo, L. Chen, C. Jin and Y. Lv, Hexagonal $\mathrm{SrFe}_{12} \mathrm{O}_{19}$ ferrites: Hydrothermal synthesis and their sintering properties, J. Magn. Magn. Mater., 2013, 332, 186-191.

25 L. Cao, Y. Zeng, C. Ding, R. Li, C. Li and C. Zhang, One-step synthesis of single phase micro-sized $\mathrm{BaFe}_{12} \mathrm{O}_{19}$ hexaplates via a modified hydrothermal approach, Mater. Chem. Phys., 2016, 184, 241-249.

26 M. L. Wang, Z. W. Shih and C. H. Lin, Reaction-mechanism producing barium hexaferrites from geothite and barium hydroxide by hydrothermal method, J. Cryst. Growth, 1993, 130, 153-161.

27 M. L. Wang, Z. W. Shih and C. H. Lin, Kinetics of producing barium hexaferrite in a low alkaline concentration by hydrothermal method, J. Cryst. Growth, 1992, 116, 483-494.

28 M. Drofenik, M. Kristl, A. Znidarsic, D. Hanzel and D. Lisjak, Hydrothermal synthesis of Ba-hexaferrite nanoparticles, $J$. Am. Ceram. Soc., 2007, 90, 2057-2061.

29 T. J. Perez-Juache, I. Betancourt, S. A. Palomares-Sanchez, M. M. Garcia, J. A. Matutes-Aquino and A. L. GuerreroSerrano, Study of Microstructure and Magnetic Properties of SrM Hexaferrites with Neodymium Oxide, J. Supercond. Novel Magn., 2011, 24, 2325-2329.

30 S. Kong, P. Zhang, X. Wen, P. Pi, J. Cheng, Z. Yang and J. Hai, Influence of surface modification of $\mathrm{SrFe}_{12} \mathrm{O}_{19}$ particles with oleic acid on magnetic microsphere preparation, Particuology, 2008, 6, 185-190.

31 S. Anand, S. Pauline, V. M. Vinosel and M. A. Janifer, Structural Rietveld Refinement and Vibrational Study of $\mathbf{M -}$ Type $\mathrm{BaFe}_{12} \mathrm{O}_{19}$ Nanoparticles, Mater. Today: Proc., 2019, 8, 476-483.

32 J. M. Li, A. C. H. Huan, L. Wang, Y. W. Du and D. Feng, Interface effects on magnetoresistance and magnetic-fieldreduced Raman scattering in magnetite, Phys. Rev. B: Condens. Matter Mater. Phys., 2000, 61, 6876-6878.

33 J. Kreisel, G. Lucazeau and H. Vincent, Raman spectra and vibrational analysis of $\mathrm{BaFe}_{12} \mathrm{O}_{19}$ hexagonal ferrite, J. Solid State Chem., 1998, 137, 127-137.

$34 \mathrm{~J}$. M. Li, Mass production of graphene-like single-crystalline $\mathrm{NbSe}_{2}$ (004) nanosheets via intercalant-assisted thermal cleavage, Appl. Phys. A: Mater. Sci. Process., 2010, 99, 229-235.

35 J. M. Li and J. Fang, Anthracene-assisted inverse transport growth and superconductivity at $3.3 \mathrm{~K}$ in unsupported ultrathin $\{110\} \mathrm{Nb}$ and $\{0001\} \mathrm{NbSe}_{2}$ nanoplates, J. Mater. Chem. C, 2017, 5, 9545-9551.

$36 \mathrm{~J} . \quad$ M. Li, Robust 2D Room-Temperature Dilute Ferrimagnetism Enhancement in Freestanding Ammoniated Atom-Thin 0001 h-BN Nanoplates, ACS Appl. Mater. Interfaces, 2017, 9, 39626-39634. 